\title{
Research on the Construction of Innovation Education Curriculum System in Science and Engineering
}

\author{
Zhang Ming \\ Depart of Electronic Information Science and Technology \\ of SHEN YANG University \\ SHEN YANG University \\ Shenyang 110044, china \\ Zhming_1963@163.com
}

\author{
Ma Yao \\ Depart of Electronic Information Science and Technology \\ of SHEN YANG University \\ SHEN YANG University \\ Shenyang 110044, china \\ 1368882773@QQ.com
}

\author{
Chen Honglei \\ Depart of Electronic Information Science and Technology of SHEN YANG University \\ SHEN YANG University \\ Shenyang 110044, china \\ 964682835@QQ.com
}

\begin{abstract}
- with the transformation the educational reform of and development of colleges and universities, cultivating applied talents is the goal and purpose of curriculum system reconstruction. The structure and content of curriculum system are reformed. The combination of production and teaching for the path, innovative teaching methods and means, combined with the actual needs of professional education and teaching reform to explore the construction of integration courses, professional courses, innovative practice, entrepreneurial experience as one of the innovative entrepreneurship education curriculum system to explore innovative practice for students. It is of great significance to inspire students to discover and expand, and actively participate in innovation and creation.
\end{abstract}

Keywords-innovation; education; curriculum; Construction

\section{INTRODUCTION}

Curriculum system is the carrier to achieve the training objectives, reflects the orientation of the school running, the content reflects the objectives, specifications and models of personnel training, the science of the course system is directly related to whether the personnel training standards to achieve educational goals Claim. The construction of curriculum system is the central link and important field of talent training mode reform. Based on the transformation and development of colleges and universities, and based on the specialty construction of science and engineering, this paper constructs a curriculum system that integrates the characteristics of production and teaching innovation. It can provide some theoretical references for related universities and relevant professional curriculum system construction, at the same time, enrich the curriculum The Construction of System Content.

\section{PARTICULAR SIGNIFICANCE}

In the transformation and development of higher education in the teaching reform, to carry out innovative features of the integration of school-enterprise curriculum system is of particular significance ${ }^{[1]}$. Specific from the following aspects of reform

\section{A. Change "knowledge-based" curriculum system as "engineering practice education" curriculum system}

This paper analyzes the teaching of higher education in our country. The choice of curriculum content is limited by the knowledge standard. The curriculum system builders pay more attention to the knowledge integrity and emphasize the "subject center" and "knowledge center". The selection of teaching contents and the compilation of teaching materials attach too much importance to the completeness and systematization of knowledge. This kind of curriculum system based on knowledge-based thought emphasizes imparting knowledge in curriculum content, teaching organization and implementation. Second, the lack of engineering science and technology personnel for the pre-training necessary for the overall consideration of the combination of subject knowledge and engineering practice is extremely lacking content. In this regard, the lack of engineering education, the lack of professional knowledge, the community rich engineering cases in the books in the traces of hard to find, engineering practice caused by new problems and new thinking is almost blank. The curriculum system proposed in this paper starts from the knowledge system and focuses on the cultivation of the "engineering practice education" system for the students' comprehensive application of knowledge, and constructs the curriculum system with the contents of the knowledge teaching and practice teaching. 
B. Increase the coupling between courses in the vertical and horizontal directions

In order to solve the problem that the curriculum system has a relatively independent orientation and loosely interrelated courses, it is necessary to consider the relationship between the pre-course and the follow-up in the course arrangement and arrangement, taking into account the coupling between courses, professional development of the curriculum, Selection, teaching and other aspects of the implementation of the course in addition to a course to consider their own position and objectives, but also taking into account the curriculum system and the integrity of the overall arrangement to complete the organic link between the curriculum and content, the overall response organization, But also to form a knowledge chain, knowledge system, and the complexity of today's engineering practice and integrated in line with, to ensure that the course of knowledge, Which will help to strengthen the students' comprehensive engineering practice ability.

\section{To build a joint platform for schools and enterprises to complete the practice-related teaching content}

Relying on enterprise engineers with a high level, solve the integrated experimental and engineering training platform for the problem, and enterprises to reach a cooperation agreement, by the enterprise engineers and team teachers to teach the integration of teaching and research team. Improve the theoretical teaching and practice teaching in the proportion of comprehensive practical teaching content in the theoretical teaching of the introduction of cutting-edge knowledge and practical cases in the experimental class, increase the proportion of integrated and design-based experiments, an increase of multiple professional comprehensive training, Module integrated training project. In the professional comprehensive training, module comprehensive training project, the understanding of practice, production practice, graduation practice and graduation design links with enterprise engineers in teaching, with the enterprise platform to strengthen teaching and engineering practice, and strive to make students social engineering practice Ability to be in the school system training, improve engineering practice and engineering quality, to meet the needs of high-quality applied talents.

\section{Curriculum evaluation trend "application, innovation" assessment}

The students participate in the project, competition, scientific research and innovation activities and academic evaluation of the combination of performance in the curriculum examination to be reflected. Students integrated application of the assessment is no longer determined by a paper, the assessment of student learning is not only to re-results more important process. The course evaluation is based on the results of "teaching and learning", and is carried out in the evaluation content, evaluation form and evaluation process. It emphasizes the comprehensive application of theory and practice knowledge, innovation ability and operation skill, and tries to reflect it through examination. Students of the real ability to develop students to take the initiative to learn, participate in the activities of enthusiasm, to achieve a good style of study. Will be one-time assessment process into a process-based assessment, with multiple quality concept to replace a single view of quality to complete the evaluation of the change.

\section{THE REFORM SHOULD ACHIEVE THE FOLLOWING OBJECTIVES}

\section{A. School - enterprise integration, to build a curriculum system to meet the needs of industrial development}

According to the engineering characteristics of science and engineering specialty, the principle of curriculum system construction aiming at cultivating comprehensive engineering practice ability and innovation ability is established, the core curriculum is optimized, and the curriculum combining quality core curriculum and quality development course is designed. System, reflecting the ability to re-practice, re-effect of the training concept; to promote students' ability to improve and expand the quality of the job requirements with the enterprise adaptive integration, the maturity of the enterprise case, the process of cases, the generation of cases into the curriculum In the part of the practice, training courses and students in the graduation project design to "business proposition, students complete, double-double, double-click, double-click, Teacher guidance, market testing, "the basic principles to complete the course content guidance.

\section{B. Integration of course content, the formation of modular series of courses}

In order to increase the coupling degree between the courses, five basic curriculum modules, basic course series, professional course series, practical training series course, practical project course series, and innovative design series curriculum module are established to reconstruct the curriculum system.

Basic courses include humanities and social science knowledge, basic knowledge of mathematics, related fields of knowledge, this series of courses to cultivate students' comprehensive literacy; professional courses are professional basic course, professional knowledge group, professional knowledge group, professional innovation knowledge class Practice, training, practical training, graduation practice, graduation design, this series of courses to cultivate students' hands-on ability. Practical training courses are mainly experimental courses, curriculum design, practical training, graduation practice, graduation design. The series of courses are designed to train students' comprehensive system design and development ability; the innovative design series of practice curriculum modules mainly include innovation and entrepreneurship education, professional knowledge innovation design, and comprehensive project design, which are mainly composed of engineering training and professional related project design. Innovation and design courses mainly complete the training of students' ability to innovate.

In the framework of professional training objectives, for different modules, the development of different objectives of the curriculum, sub-module, set the objectives of the course group construction, to ensure that the local curriculum group construction goals and objectives of the overall curriculum and 
coordination of the conditions, Reflect the role of different modules of the curriculum, to avoid duplication of knowledge.

\section{Open the second classroom teaching, training students' practical ability and innovative spirit}

By building up the second course teaching system, the students' self-study ability, innovative spirit and practical ability can be cultivated. The research group uses two classrooms to carry out teaching, to achieve the first class, the second classroom and school education combined education system. The first class teaching content is carefully selected and the second class task is carefully designed. The students are trained to participate in the discipline competition, extracurricular professional activities and students 'scientific research projects, so as to cultivate the students' practical ability, self-learning ability and innovation ability ${ }^{[2]}$.

\section{Increase the proportion of practical teaching, students' comprehensive engineering practice ability}

The three-stage and three-level practical course system of conceptual training, skill training and project training is carried out around the curriculum system. The training course is carried out from year to year, from conceptual training to technical training. In the training of students' practical ability and project implementation ability, the real project of the enterprise is collected as a teaching case, and the students are completed step by step according to the actual implementation process of the project. Through the project development, learning knowledge and exercise ability are developed, and a similar case is developed as student practice contention, allowing students to simulate the realization of students in the process of doing the project, subtle to the students the ability of comprehensive engineering practice.

\section{THE PROBLEM TO SOLVE}

\section{A. Establishing the Curriculum System of School - Enterprise}

Relying on the combination with enterprises, combined with their own orientation of student training, focusing on solving the three-dimensional structure of engineering practice knowledge structure, relying on professional training objectives and teaching plans have developed, with reasonable courses and course system for students to create a more complete The professional theory and practice knowledge platform for school-enterprise joint construction base training courses, training content, training programs to create innovative conditions for the implementation of the project.

\section{B. To complete the transformation and development as the goal of the curriculum system model}

Combining with the development orientation of the school and the transformation and development of the school, the curriculum system is divided into five courses modules: basic courses, professional courses, practical training courses, practical project courses and innovative design courses. According to each module the specific requirements of the theory and practice to determine the content and around the practical ability, practical skills and ability to innovate the core of the progressive development work.

\section{The Construction of Innovation Training Platform with the Goal of Engineering Comprehensive Practical Ability and Innovative Ability Training}

It is planned to carry out the innovation and entrepreneurship competition platform for students of all grades in a planned and planned way, to devise different innovative and entrepreneurial practice plans for different types of students, to carry out the three-dimensional construction of innovation and entrepreneurship, and to draw lessons from them. Construction to do further improvement work.

\section{AN EMBODIMENT, AN IMPLEMENTATION METHOD}

\section{A. School-enterprise cooperation, the integration of production and education path}

Joint enterprises, through the establishment of cooperation between schools and enterprises to build classes and build a base in the school, the establishment of student internships, training platform, to create a set of "teaching, production, research" in one integrated platform for innovative practice for students The implementation of the system to build the necessary scenes. This paper constructs an application-oriented talent cultivation mode and a dual-subject curriculum mode, which combines the real case with the case-based teaching and opens the thinking wisdom of the students to improve their theoretical solution.

\section{B. Engineers on the podium}

Teachers are the key to promote the implementation of the new curriculum system ${ }^{[3]}$. The implementation of the new curriculum system requires teachers to change from "moving" to "doing", from "I see you do" to "see me do, do with me" These changes require dual-teacher dual-energy teachers, and dual-teacher training needs of the process, more time. To solve this problem, the task group to be based on the needs of professional courses, the introduction of enterprises with engineering background of engineers to enter the classroom to ensure the implementation of the new curriculum.

\section{Curriculum resources development applied to teaching}

To promote the use of resources to promote the application of resources to promote the construction of curriculum resources to professional core courses for the lead, focusing on the construction, including curriculum, teaching cases, teaching video, experimental guidance, exercises, etc., for the implementation of the new curriculum content basis.

Teaching materials from the learning objectives, the main content, case selection, description of the task, and so on, to promote the construction of the teaching materials of the teaching materials, Task analysis, implementation plan, training projects, exercises and other aspects of the preparation.

\section{Innovation of Examination Mode, Guarantee of Reform}

The strong theoretical courses are written examination, and practical skills, such as applied knowledge, applied ability, 
practical ability and operational skills, are proposed to be assessed by means of practice assessment or process evaluation. They can also take the form of oral examination or reply. In addition, students participate in the project, competition, scientific research and innovation activities can also be used as a basis for evaluation of evaluation results. Students determine the final score is the cumulative result, or design work results and reply performance and so on. The reform and innovation of this assessment means to strengthen the "process control", weakening the examination results, in order to improve the students' enthusiasm, initiative and timeliness.

\section{CONCLUSION}

The construction of school-enterprise integration curriculum system, can improve the transformation of curriculum group construction whose goal is development.
Innovation, entrepreneurship education and professional education can be combined to strengthen the student's practical ability and creative ability.

\section{REFERENCES}

[1] liuyang. On the Construction of "Signal Detection and Processing" in Journal of Shenyang University: Social Science Edition", 2010, 12 (1): 92-94

[2] Zhang Jingqun. Research on the Construction of College Students 'Innovative Education Curriculum System. "Chinese College Students' Employment: Theoretical Edition" 2015 (20)

[3] Zhang Ming, Yang Guangying.Study on the development of specialties in science and engineering innovation and entrepreneurship, Modern Vocational Education, 2016 (3): 125-126 